\title{
A NOVEL HIGH EFFICIENCY CONVERTER FOR RENEWABLE ENERGY GENERATION APPLICATIONS
}

\author{
Chaitanya.M.K. ${ }^{1}$, A.Kumar ${ }^{2}$ \\ ${ }^{1}$ M.Tech Student, EEE, BNM Institute of Technology, Karnataka, India \\ ${ }^{2}$ Associate Professor, EEE, BNM Institute of Technology, Karnataka, India
}

\begin{abstract}
Resonant converters are those, which has the L and C components that would provide a sinusoidal voltage or current wave during any sub interval in the switching interval. These wave form help in obtaining the Zero Voltage and Zero Current Switching to occur in the converters. The topology of the resonant converters uses the different combination of inductor and capacitors to obtain this property. The combination of this inductor and the capacitor is called the resonant tank. This project is to develop such a resonant converter, which utilizes the LLC resonant tank. This is a full bridge topology, which is a isolated topology in $D C-D C$ converter topology. The isolation is happening because of the high frequency transformer placed between the inverter in the sourceside and the converter in the load side. The high frequency is obtained by switches of inverter in HF mode to supply to the source of the HF transformer. The multiphase converters are the main source that is used in the high performance point of load converters. This project uses the two-phase converter, which would split the current path into two in the source side. As the two currents join in the output capacitor the ripple at the output is reduced to half the value as the frequency of the ripple is doubled.The simulation work was carried out for both high efficiency LLC converter and full bridge converter of $14 \mathrm{~V}$ input. Here, the efficiency of both the converters are calculated and was proved that efficiency of proposed system is higher than that of resonant converter of full bridge.
\end{abstract}

Keywords: High Efficiency Converter, Resonant Converter For Full Bridge, Efficiency, Output Current Ripple and PWM Control

\section{INTRODUCTION}

The DC-DC converter starts from Buck, Boost, Buck Boost and SEPIC topology, which has its performance, improved for every improvement in the topology. The interleaved converter is one such improvement that has been exclusively used for high performance load like the low voltage high current applications that are also called the point of load converters. These kinds of converters are having low output capacitor ripple characteristics as the two or more inductors would be supplying the output capacitor.

Renewable energy resources are almost the most important and the most needed alternative as the need of these kind of unconventional energy resource would fulfill the gap that has been created because of the energy demand prevailing today.

As we know,renewable energy sources requires dc-dc converter for its interfacing.Compared to other converters, high efficiency LLC resonant converter is the best choice, as the name indicates it has high efficiency,low output current ripple. Source switches and load diodes can obtain turning ON of ZVS and turning OFF of ZCS, which reduces losses of switches and losses due to $\mathrm{dv} / \mathrm{dt}$.In this method,frequency will be fixedand which is equal to that of resonant frequency does optimization of magnetic components for losses.

\section{DESCRIPTION OF PROPOSED SYSTEM}

The two-stage inserted boost converter and resonant converter of full bridge forms high efficiency converter system. The left leg and right leg of the system is formed by switch pairs $\mathrm{S} 1, \mathrm{~S} 2$ and $\mathrm{S} 3, \mathrm{~S} 4$ respectively.To form first boost converter,inductor Lb1 is joined to centre of first leg and inductor Lb2 is joined to centre of second leg to form second boost converter.Both the boost converters are phase shifted with $180^{\circ}$.The LLC resonant tank, HF transformer T,diodes of rectifier Do1,Do2 and the two legs form a resonant converter of full bridge.Here,number of power switches are reduced by sharing same number of switches by both resonant converter of full bridge and two-satge inserted boost converters. Hence, size of the system can be reduced and also the cost of the systemcan be reduced.

The top switch and bottom switch of each leg works inversely with a time period tdead.Switches S1and S3 are phase shifted with $180^{\circ}$ and maintains the duty cycle D .Similarly,switches S2 and S4 are $180^{\circ}$ out of phase and have same duty cycle 1-D.Alternating current of three level square wave with magnitude Vbus is produced by input resonant tank voltage utank with duty cycle $\mathrm{D}$ (for $\mathrm{D} \leq 0.5$ ) or 1-D (for $\mathrm{D}>0.5$ ).For altering, $\mathrm{D}$ and magnitude of utank,duty cycle of switches S1 and S3 can be adjusted. 


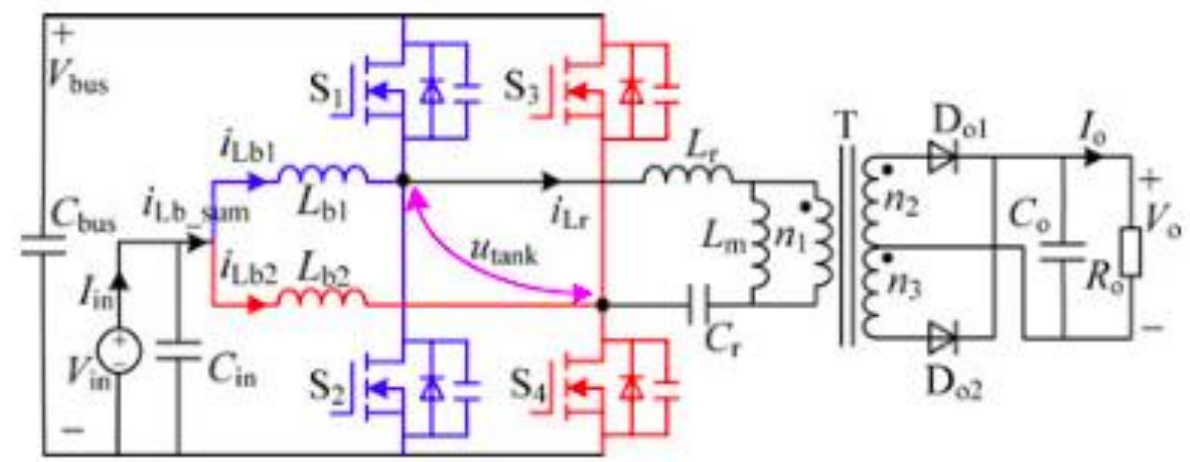

Fig 1. Circuit of the proposed system

\section{RESONANT CONVERTER OF FULL BRIDGE}

Figure2 shows a resonant converter of full bridge with rectifier of full bridge. In a simplistic discussion, waveform of square is produced by bridge of switching to energize the resonant tank of LLC, which will output a current, which is sinusoidal in nature that is magnified and verified by the rectifier and transformer circuit.Alternating current is cleared by the filters of output capacitors and which inturn produces a direct current voltage.
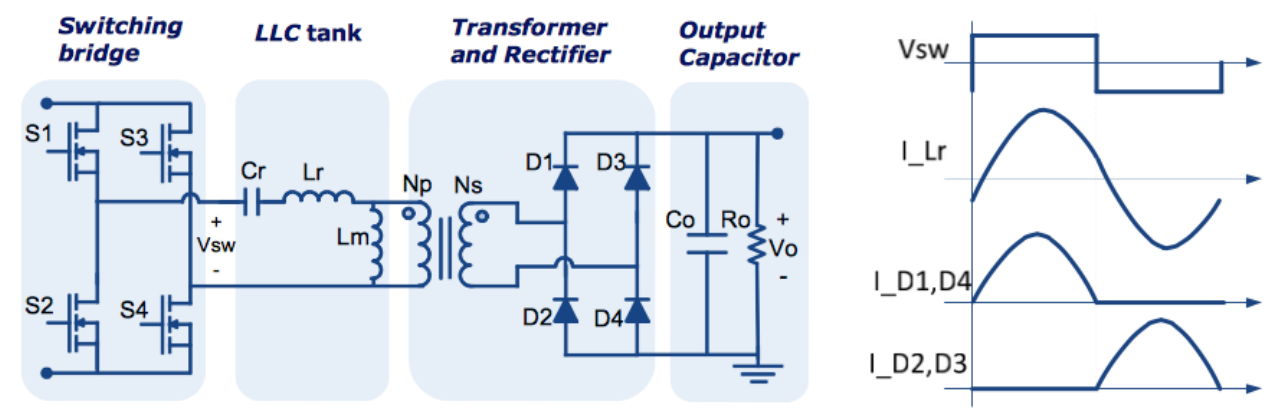

Fig2. Circuit of resonant converter of full bridge

Power delivery operation, firstly which occurs when resonant tank is energized with a positive voltage during switching cycle which causes resonant current to be in the positive direction during first half cycle and secondly, magnetizing current will be increasing and decreasing respectively and inductor voltage will be the output voltage in its opposite negative and positive cycle.

The freewheeling operation is possible only if magnetizing current of transformer provides a path for resonant current to reach its value, this only happens when $\mathrm{fs}<\mathrm{fr}$, causing the secondary of transformer current to attain its zero value and load side rectifier to disconnect,consequently the magnetizing inductor will be free to enter the resonance with the resonant inductor along with the resonant capacitor.The frequency of original resonance is more than the frequency of second resonance particularly when magnetizing inductor is very much greater than that of resonant inductor. Thus, during this operation only source current changes in a small amount and can be approximated to be unchanged for simplicity.

\section{DESIGN STEPS}

The steps for designing the high efficiency converter is mentioned below.

Source voltage $\mathrm{V}_{\text {in }}=14 \mathrm{~V}$,Switching frequency $=100 \mathrm{KHz}$ and High-frequency transformer T:N1=27,N2=N3=2.
Inductor current ripples

$$
\begin{aligned}
\Delta \mathbf{i L b 1}, 2 & =\frac{\operatorname{Vin}(\mathbf{1}-\mathbf{D})}{\mathbf{f s} \times \mathbf{L b 1}, \mathbf{2}} \\
\mathrm{Lb} 1,2 & =\frac{\operatorname{Vin}(1-\mathrm{D})}{\mathrm{fs} \times \Delta \mathrm{iLb} 1,2}
\end{aligned}
$$

Duty cycle isin the range ofD $=0.34-0.67$

Approximately, $\mathrm{D}=0.4$

Therefore, Inductor 1 and 2 value are

$=\mathrm{Lb} 2=271 \mathrm{uH} \cong 32 \mu \mathrm{H}$

$$
\mathrm{Lb} 1,2=\frac{14(1-0.4)}{100 \times 10^{3} \times 2.65}
$$

Switching frequency ( fs $)=$ Resonant frequency $(\mathrm{fr})=$ $100 \mathrm{KHz}$

$$
2 \pi \mathrm{fr}=\frac{1}{\sqrt{\mathrm{LrCr}}}
$$

Approximating, Resonant capacitor $(\mathrm{Cr})=50 \mathrm{nF}$

Substituting in the above equation

$\mathrm{Lr}=50.7 \mu \mathrm{H}$

Cin has to withstand voltage $14 \mathrm{~V}$.Usually, the capacitor must have the voltage range of $1.5 \times($ actual voltage $)$

$\therefore \mathrm{C}$ in $=1.5 \times 14$

$=21 \mathrm{~V}$

Co also has the same criteria

$$
\begin{aligned}
\therefore C o & =1.5 \times 1.918 \\
& \cong 3 \mathrm{~V}
\end{aligned}
$$




\section{SIMULINK MODEL USING MATLAB SIMULINK}

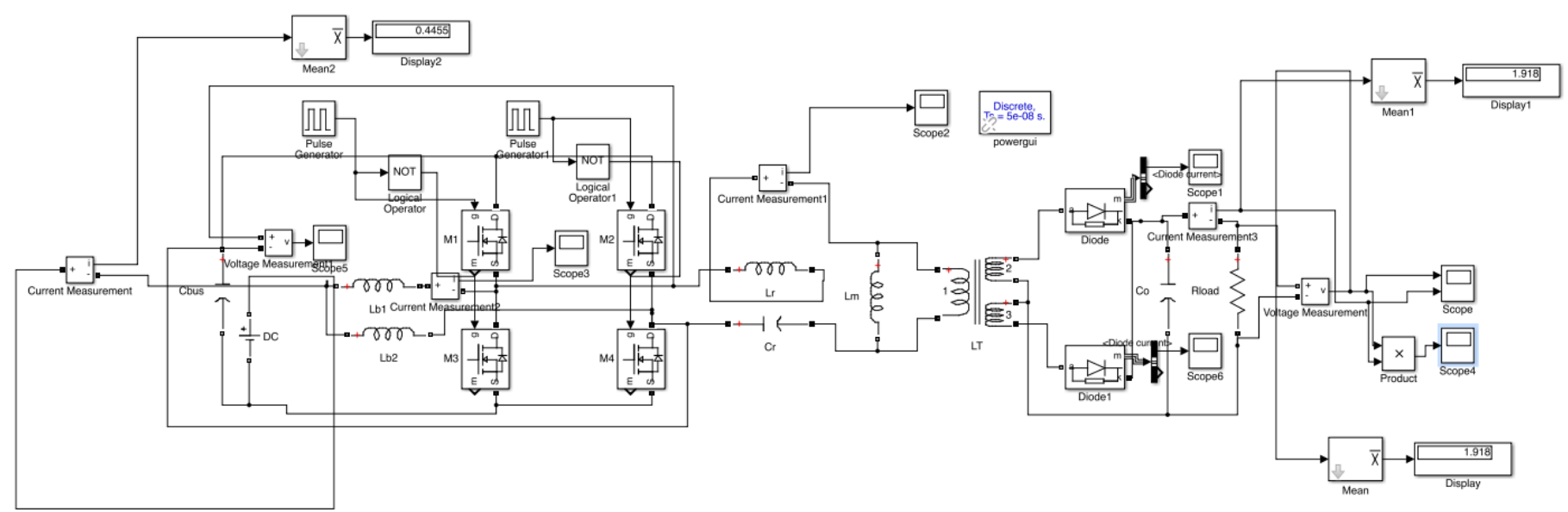

Fig 3. Simulation model for proposed system

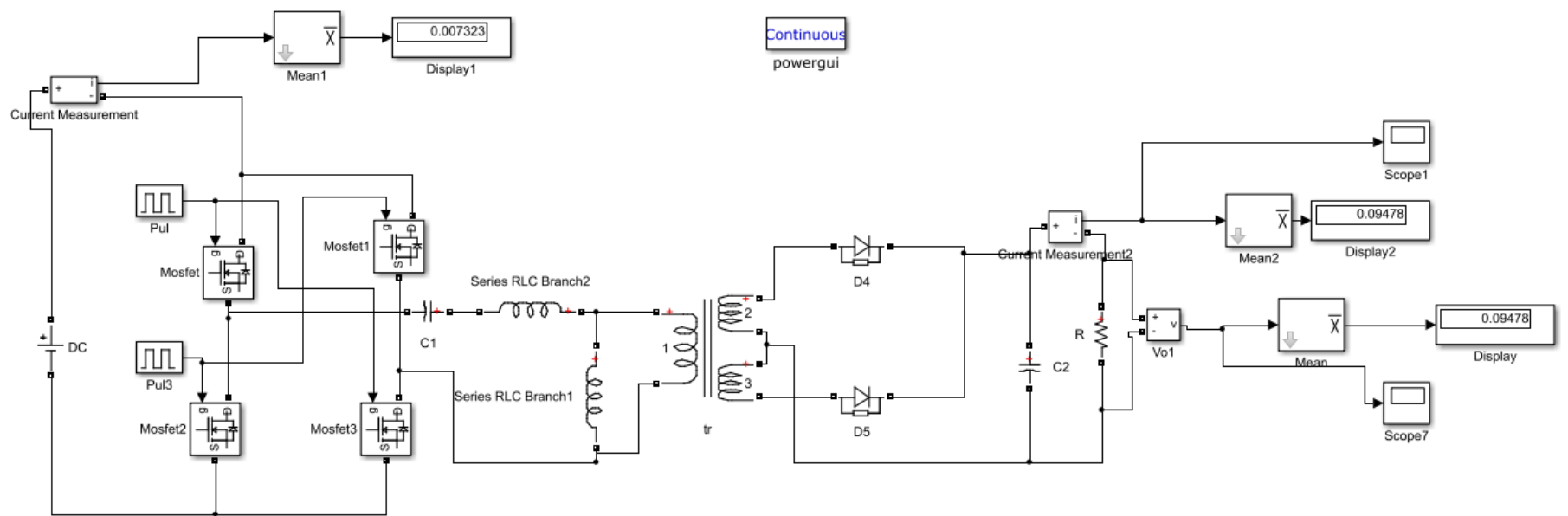

Fig4. Simulation model for full bridge LLC resonant converter

\section{SIMULINK RESULTS}

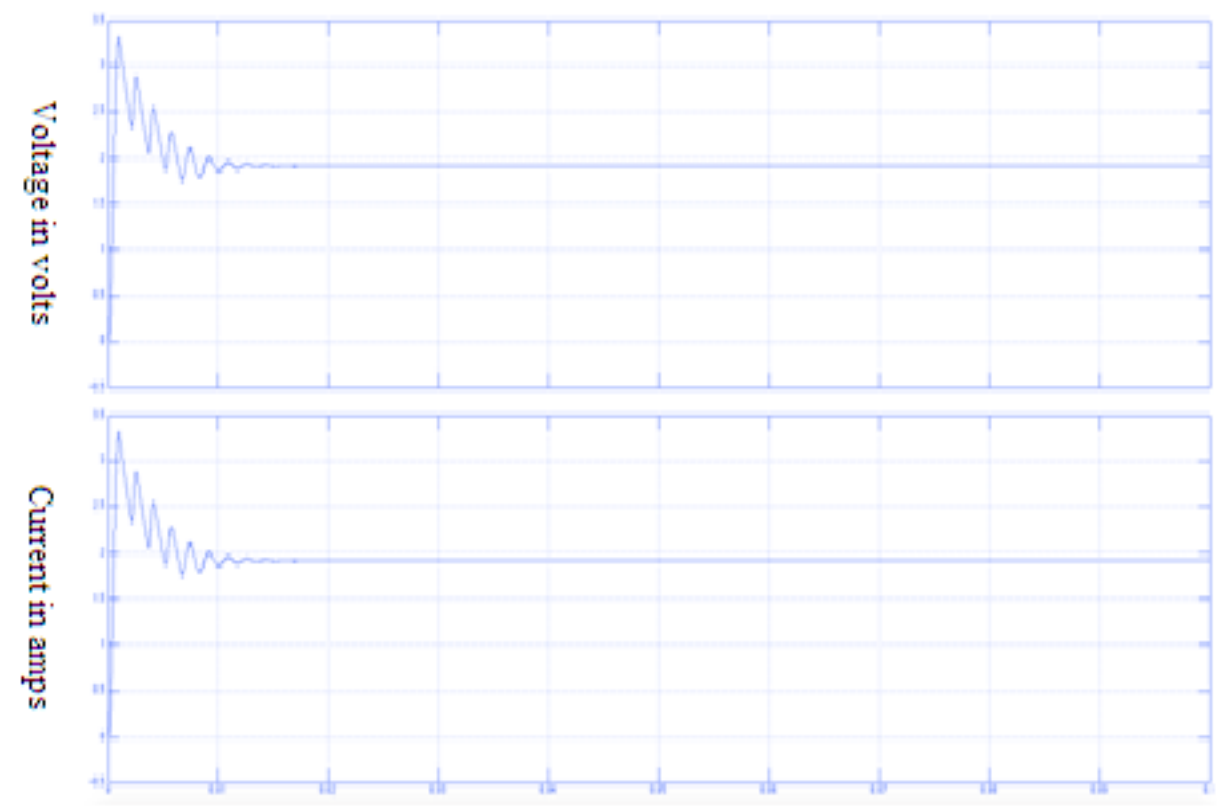

Time in seconds

Fig 5. Voltage and current waveforms of proposed system 


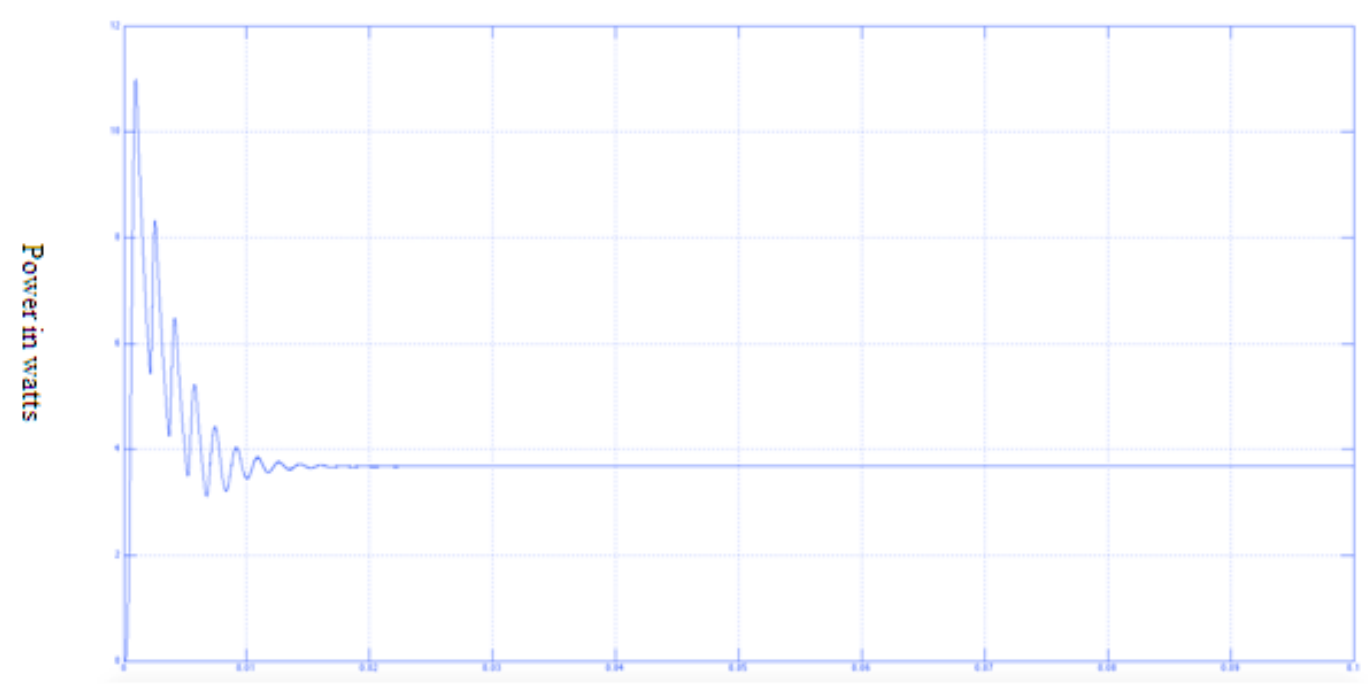

Time in seconds

Fig 6. Power waveforms of proposed system

Efficiency calculation of proposed system

Input current $\operatorname{Iin}=0.4455 \mathrm{~A}$

Input voltage $\mathrm{Vin}=14 \mathrm{~V}$

Output current Io $=1.918 \mathrm{~A}$

Output voltage $\mathrm{Vo}=1.918 \mathrm{~V}$

Efficiency $=\frac{\text { Vo } \times \text { Io }}{\text { Vin } \times \text { Iin }}=\frac{\text { Po }}{\text { Pin }}$

$=\frac{1.918 \times 1.918}{14 \times 0.4455}$

$=0.589822$

$=58.9822 \%$
Efficiency calculation of Full bridge LLC Resonant Converter

Input current $\operatorname{Iin}=0.007359 \mathrm{~A}$

Input voltage $\mathrm{Vin}=14 \mathrm{~V}$

Output current Io $=0.09486 \mathrm{~A}$

Output voltage $\mathrm{Vo}=0.09486 \mathrm{~V}$

Efficiency $=\frac{\text { Vo } \times \text { Io }}{\text { Vin } \times \text { Iin }}=\frac{\text { Po }}{\text { Pin }}$

$=\frac{0.09486 \times 0.09486}{14 \times 0.007359}$

$=0.087341$

$=8.7341 \%$

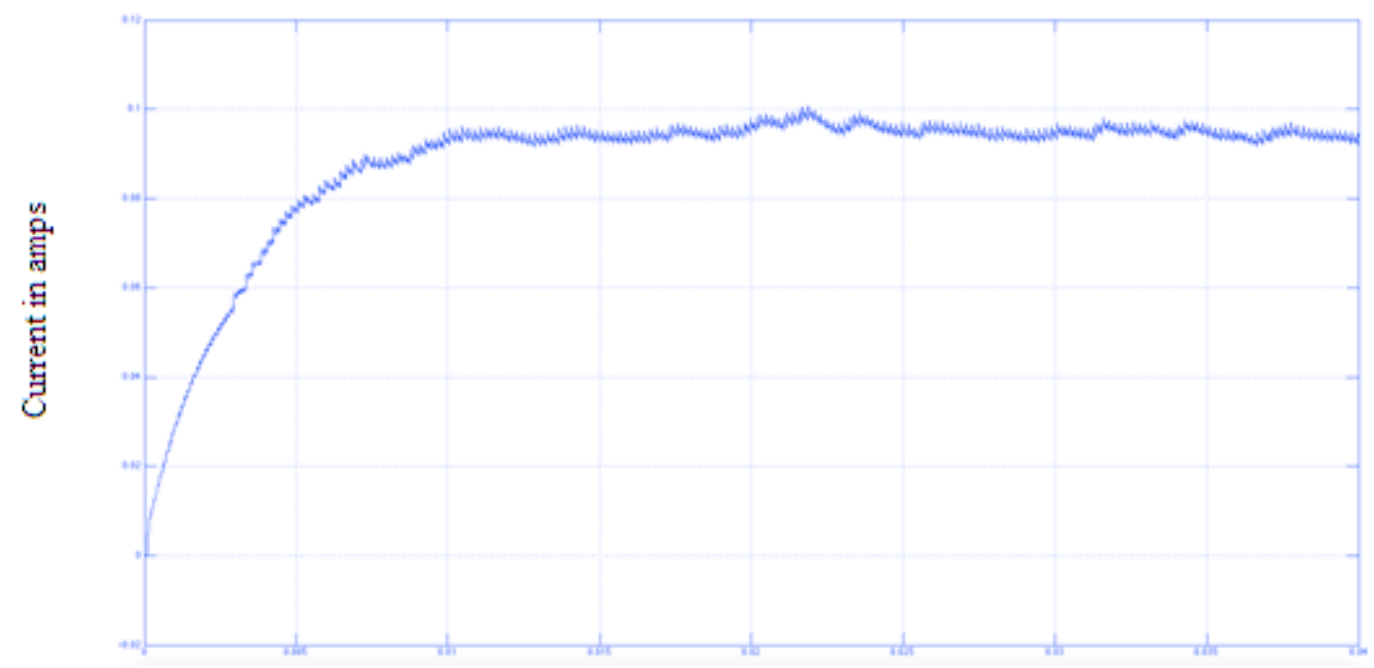

Time in seconds

Fig 7. Waveform of current for resonant converter of full bridge 


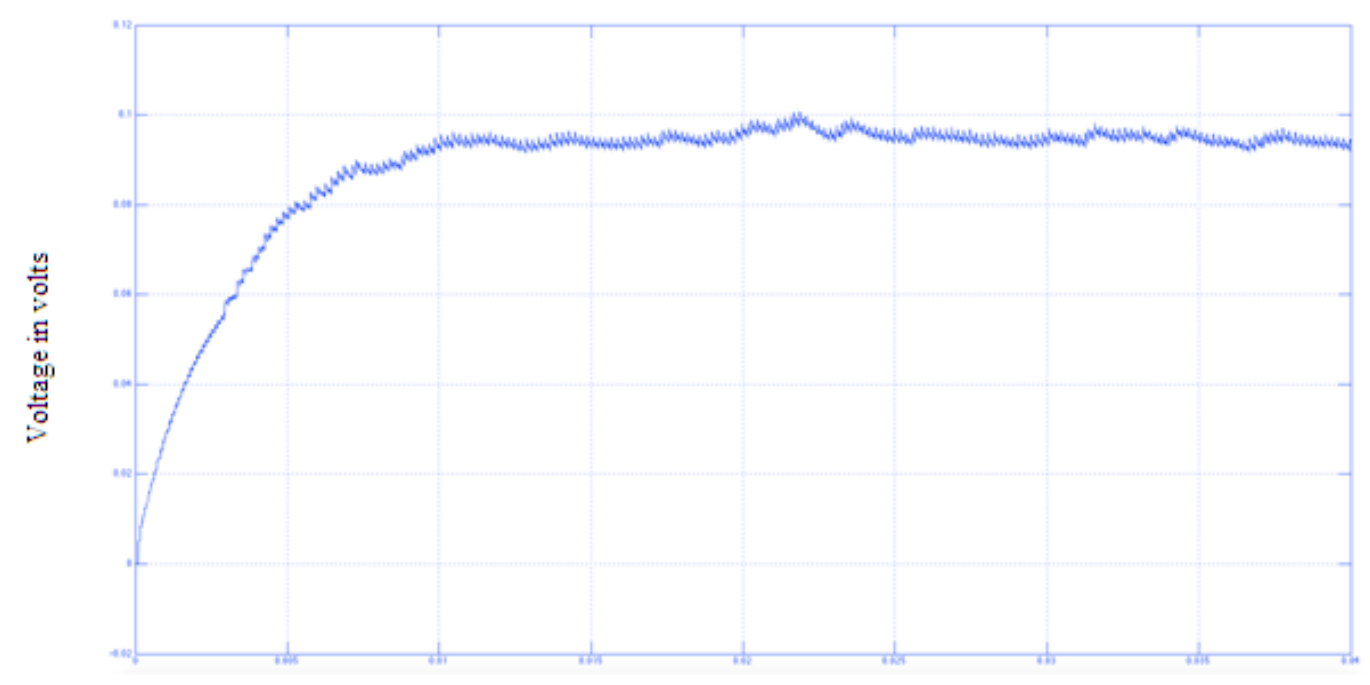

Time in seconds

Fig 8. Waveform of voltage for resonant converter of full bridge

By comparing the results of both the converters, itis proved that efficiency of high efficiency converter is more compared to that of resonant converter of full bridge.Thus,high efficiency of proposed is achieved.

\section{CONCLUSIONS}

High efficiency converter is developed in this paper.Due to the addition of two stage inserted boost converters into the resonant converter of full bridge,output current ripple is reduced and efficiency is improved.The simulation work was carried out to show that proposed high efficiency converter is more efficient than resonant converter of full bridge and low output current ripple is also obtained.Therefore, renewable energy resources can use proposed high efficiency LLC resonant converter for its interfacing.

\section{ACKNOWLEDGEMENT}

We would like to thank the BNM Institute of Technology and Electrical \& Electronics Department research members for their encouragement and support in providing MATLAB Simulink software to carry out this simulation work of high efficiency converter.

\section{REFERENCES}

[1] J.M. Carrasco, L. G. Franquelo, and J. T. Bialasiewicz, "Power electronicsystems for the grid integration of renewable energy sources: A survey,"IEEE Trans. Power Electron., vol. 53, no. 4, pp. 1002-1016, Aug. 2006.

[2] Y. Chuang, Y. Ke, H. Chuang, and Y. Wang, "A novel single-switchresonant power converter for renewable energy generation application".

[3] C. N.M. Ho, H. Breuninger, S. Patterson, G. Escobar, L. A. Serpa, and A.Coccia, "Practical design and implementation procedure of an interleavedboost converter using SiC diodes for PV applications," IEEE Trans. PowerElectron., vol. 27, no. 6, pp. 2835-2845, Jun. 2012.

[4] P.-W. Lee, Y.-S. Lee, D. Cheng, and X. Liu, "Steadystate analysis ofan interleaved boost converter with coupled inductors," IEEE Trans. Ind.Electron., vol. 47, no. 4, pp. 787-795, Aug. 2000.

[5] W. Feng, F. C. Lee, and P. Mattavelli, "Simplified optimal trajectory control(SOTC) for LLC resonant converters," IEEE Trans. Power Electron., vol. 28, no. 5, pp. 2415-2426, May 2013.

[6] Z. Hu, Y. Qiu, Y.-F. Liu, and P. C. Sen, "A control strategy and designmethod for interleaved LLCconverters operating at variable switchingfrequency," IEEE Trans. Power Electron., vol. 29, no. 8, pp. 4426-4437,Aug. 2014.

[7] D. Huang, S. Ji, and F. C. Lee, " $L L C$ resonant converter with matrixtransformer," IEEE Trans. Power Electron., vol. 29, no. 8, pp. 4339-4347,Aug. 2014.

[8] D. Wang and Y.-F. Liu, "A zero-crossing noise filter for driving synchronousrectifiers of $L L C$ resonant converter," IEEE Trans. Power Electron.,vol. 29, no. 4, pp. 1953-1965, Apr. 2014. 